\title{
Cochlear Kainate Receptors
}

\author{
Marcello Peppi, Melissa landa, and William F. Sewell \\ Department of Otology and Laryngology, Eaton Peabody Laboratory, Massachusetts Eye and Ear Infirmary and Harvard \\ Medical School, 243 Charles Street, Boston, MA 02114, USA
}

Received: 19 October 2010; Accepted: 14 December 2011; Online publication: 10 January 2012

\begin{abstract}
Synaptic transmission between the cochlear hair cell and its afferent fiber is mediated by glutamate receptors. While kainate receptors are known to be present in the spiral ganglion, little is known of their distribution or functional role. We have detected all five kainate receptor subunits in the mouse cochlea with quantitative RT-PCR and with immunohistochemistry. We observed kainate receptors on afferent terminals co-localized with $\alpha$-amino-3-hydroxy-5-methyl-4-isoxazolepropionic acid (AMPA) receptors at the afferent synapse. Individual terminals innervating a single hair cell varied in their ratios of AMPA to kainate receptor immunoreactivity. Infusion of the mouse cochlea via the scala tympani with UBP296, a recently developed antagonist with high specificity for the GluK1 kainate receptor (compared to the AMPA receptor), reduced the compound action potential and elevated auditory neural thresholds without affecting the distortion product otoacoustic emission thresholds. Thus, the pharmacological evidence suggests that kainate receptors may contribute to the response to transmitter released from the hair cell during acoustic stimulation. It is plausible that afferent transmission at this synapse is mediated by a mix of AMPA and kainate receptors.
\end{abstract}

Keywords: immunohistochemistry, AMPA, mouse, hearing, auditory nerve, neurotransmitter, pharmacology

Correspondence to: William F. Sewell - Department of Otology and Laryngology, Eaton Peabody Laboratory - Massachusetts Eye and Ear Infirmary and Harvard Medical School - 243 Charles Street, Boston, MA 02114, USA. email: wfs@epl.meei.harvard.edu

\section{INTRODUCTION}

Synaptic transmission between the cochlear hair cell and its afferent fiber is mediated by glutamate receptors. Although all three types of ionotropic glutamate receptors ( $\alpha$-amino-3-hydroxy-5-methyl-4isoxazolepropionic acid (AMPA), kainate, and $\mathrm{N}$-methyl-D-aspartate (NMDA) appear to be present in afferent neurons, the conventional view suggests that afferent transmission is dominated by AMPA receptors (Moser et al. 2006; Ruel et al. 2007; Glowatzki et al. 2008). However, information on the presence, distribution, and role of kainate receptors in the cochlea is sparse. Kainate receptor subunits (GluK1, 2, 4, and 5) are known to be present in spiral ganglion cell bodies by in situ hybridization (Niedzielski and Wenthold 1995), but it is not known whether the receptors, once generated, are distributed at the hair cell afferent synapse, on the presynaptic terminals in the cochlear nucleus, or in both locations. Immunohistochemical analysis of ionotropic receptors in the cochlea has always been challenging. There are several reports of AMPA receptor localization in the cochlea (Matsubara et al. 1996; Knipper et al. 1997; Eybalin et al. 2004) though none of kainate receptors.

Pharmacological experiments have been limited because of a paucity, at least until recently, of agents with specificity for the kainate receptor. AMPA receptor antagonists, such as CNQX and DNQX, block both AMPA and kainate receptors with similar affinities (Honore et al. 1988). Two antagonists with some selectivity for the AMPA vs kainate receptor, GYKI 53784 and NBQX, reduce auditory nerve responses (Ruel et al. 2000; Seal et al. 2008), but the relatively low selectivities (10- and 100-fold respectively (Bleakman et al. 1996; Mayer et al. 2006)) and lack of characterization of these agents on many heteromeric kainate combinations (Pinheiro and Mulle 2006) do not allow 
one to rule out the involvement of kainate receptors in cochlear transmission.

The kainate receptor is a tetramer, comprising one or more of five different subunits. These have recently been renamed GluK1-5, corresponding to the genetic nomenclature (Grik1-5) and were formally termed (respectively) GluR5, GluR6, GluR7, KA1, and KA2 (Collingridge et al. 2009). GluK1-3 have the ability to form functional homomeric channels, while GluK4 and 5 demonstrate high affinity ligand binding but cannot form functional homomeric channels and must co-assemble with subunits GluK1, 2, or 3 to form functional channels (Dingledine et al. 1999; Pinheiro and Mulle 2006; Jane et al. 2009).

We examined the cochlear distribution of kainate receptors, quantified their mRNA levels, and analyzed the effects of a recently developed specific kainate receptor antagonist (UBP296) (More et al. 2004) on cochlear responses. We found that kainate receptors are co-localized with AMPA (GluA2 subunit) receptors in nerve terminals at the afferent synapse and that individual terminals on a single hair cell vary in their ratios of AMPA to kainate receptor. The pharmacological evidence suggests that some kainate receptors may contribute to the response to transmitter released from the hair cell during acoustic stimulation. It is plausible that afferent transmission at this synapse is mediated by a mix of AMPA and kainate receptors.

\section{MATERIALS AND METHODS}

\section{Methods}

Mixed-sex, 8-12-week-old CBA/CaJ mice, obtained from The Jackson Laboratory, were used in this study. All procedures were approved by the IACUC of the Massachusetts Eye and Ear Infirmary.

Quantitative RT-PCR. Kainate receptor subunits were measured with real-time quantitative PCR in 12-weekold adult CBA mice. The spiral ganglion and organ of Corti from both ears were dissected in RNA Later solution (Ambion), homogenized in $1 \mathrm{ml}$ of TRIZOL. The homogenate was centrifuged after adding $200 \mu \mathrm{l}$ of chloroform. Seven hundred microliters of supernatant was collected and diluted in $700 \mu \mathrm{l}$ isopropyl alcohol. These samples were then purified using RNeasy spin-columns (Qiagen, Valencia, CA, USA) following the manufacturer's protocol. The reverse transcription reaction included $40 \mu \mathrm{l}$ of cDNA, $11 \mu \mathrm{l}$ of $50 \mathrm{mM} \mathrm{MgCl} 2,20 \mu \mathrm{l}$ of dNTP mix, $5 \mu \mathrm{l}$ of $2.5 \mu \mathrm{M}$ of random primer (Invitrogen), and $1 \mu \mathrm{l}$ of superscript II (Invitrogen). The reaction was incubated in a PTC-100 programmable thermal controller (MJ Research, Inc) for $10 \mathrm{~min}$ at $25^{\circ} \mathrm{C}$, for $30 \mathrm{~min}$ at $48^{\circ} \mathrm{C}$, and for $5 \mathrm{~min}$ at $95^{\circ} \mathrm{C}$. Real-time quantification was accomplished with Platinum qPCR super mix-UDG with ROX (Invitrogen) using the following TaqMan probes obtained from Applied Biosystem (Foster City, CA, USA): GluK1 (Mm00446882_m1), GluK2 (Mm00599860_m1), GluK3 (Mm01179722_m1), GluK4 (Mm00615472_m1), and GluK5 (Mm00433774_m1). Samples were run in an ABI Prism 7700 sequence Detector (Perkin Elmer). The amount of RNA measured was normalized to the amount of tissue extracted by quantifying the $18 \mathrm{~S}$ rRNA (Applied Biosystems: HS99999901-S1). Real-time quantification generates data for each sample in a 96-well plate as a function of cycle number. Crossing thresholds were determined using Applied Biosystems software by placing a threshold line just above the noise level for all data from the plate. At this point, the investigator is blinded as to the identity of the curves.

Immunohistochemistry. Mid-modiolar paraffin sections were obtained from both cochleae of 8 12 week old CBA/CaJ mice (eight mice in total). Mice were anesthetized with ketamine $(100 \mathrm{mg} / \mathrm{kg})$ and xylazine $(10 \mathrm{mg} / \mathrm{kg})$ administered intraperitoneally. The temporal bones were removed and the cochleae dissected in cold phosphate-buffered saline (PBS). A small hole was made with a needle in the apex of the cochlea. The cochleae were perfused with $4 \%$ paraformaldehyde in $0.1 \mathrm{M}$ sodium phosphate buffer at $4^{\circ} \mathrm{C}, \mathrm{pH} 7.4$, through the round and oval windows then incubated in the same fixative for $10 \mathrm{~min}$ on a shaker. The cochleae were washed three times in cold PBS and decalcified overnight in 0.5 M ETDA. The inner ears were dehydrated through alcohol over $24 \mathrm{~h}$ and embedded in paraffin. Sections $(10 \mu \mathrm{m})$ were cut, dewaxed in xylene, rehydrated through alcohol into PBS, and incubated for $10 \mathrm{~min}$ at $90^{\circ} \mathrm{C}$ with antigen unmasking solution (H-3300) (Vector Laboratories, Inc., Burlingame, CA, USA) diluted 1:50 in deionized water.

Sections were incubated for $1 \mathrm{~h}$ in PBS with $10 \%$ goat serum and $0.3 \%$ Triton $\mathrm{X} 100$ at $37^{\circ} \mathrm{C}$ and then incubated overnight at $37^{\circ} \mathrm{C}$ with the same solution to which the following primary antibodies had been added at the corresponding dilutions: GluK1: goat polyclonal IgG anti-Glur5 (C-18) (sc7616) (diluted 1:150), Santa Cruz; GluK2: rabbit antibody anti-GluK2 (ab53092) (diluted 1:150), Abcam; GluK3: goat antibody anti-GluK3 (ab82148) (diluted 1:150), Abcam; GluK4: goat polyclonal IgG anti-KA1 (N-17) (sc-8916) (diluted 1:150), Santa Cruz; GluK5: goat polyclonal IgG anti-KA2 (C-20) (sc8915) (diluted 1:150), Santa Cruz; and GluA2: a mouse anti-glutamate receptor 2 (MAB397; diluted 1:1,000; Millipore).

The following day, after three washes in PBS, the slices were incubated with secondary antibodies at $37^{\circ} \mathrm{C}$. For the kainate receptors, GluK1, 3, 4, and 5, the 
secondary antibody was a Biotin-SP-conjugated donkey anti-goat IgG $(\mathrm{H}+\mathrm{L})$ (Jackson Immunoresearch cat \# 705-065-003; 2 h incubation, diluted 1:400), which was amplified by reaction for $2 \mathrm{~h}$ with a streptavidin Alexa Fluor 488 (Invitrogen Molecular Probes cat \# S32357; diluted 1:1,000). For GluK2, biotin-conjugated goat anti-rabbit IgG (Jackson Immunoresearch, cat \#111-065-003; dilution 1:400) was used as a secondary antibody, which was amplified with streptavidin Alexa Fluor 488 (Invitrogen Molecular Probes cat \# S32357; diluted 1:1,000). For the GluA2 receptor, the secondary antibody was a rabbit anti-mouse IgG $(\mathrm{H}+\mathrm{L})$ Alexa Fluor 568 (Invitrogen cat \# A11061; diluted 1:1,000).

Immunolabel for the kainate receptors was not robust, and there are several steps that we suspect are critical to successfully immunolabel these receptors. It is important to minimize the time between death of the animal and exposure of the inner ear to fixative in order to reduce the occurrence of swollen and burst terminals; this is a process that requires considerable practice for optimal proficiency. Short fixation times are critical to increase the probability of observing kainate immunolabel. Longer fixation times preserve terminal morphology but decrease strength of the immunolabel. Amplification with the biotin/streptavidin step and use of Alexa 488 fluorophores greatly enhanced the strength of the signal.

Drug delivery. To examine the role of kainate receptors in the cochlea, we infused antagonists for glutamate receptors into the scala tympani of the mouse cochlea using a delivery method we previously developed (Chen et al. 2006). UBP296 (Tocris), an antagonist for the GluK1 receptor, and CNQX, an antagonist for both AMPA and kainate receptors, were dissolved in artificial perilymph by adding an equimolar amount of $\mathrm{NaOH}$ to the solution. Animals were anesthetized with ketamine $(100 \mathrm{mg} / \mathrm{kg}$, i.p.) and xylazine $(10 \mathrm{mg} / \mathrm{kg}$, i.p.). A ventral skin incision was made longitudinally to expose the tympanic bulla via a surgical approach we described in detail in a previous publication (Chen et al. 2006). A cochleostomy was drilled $\sim 300 \mu \mathrm{m}$ beneath the stapedial artery stump. We used a beveled drill bit (Drill City, Chicago, IL, USA, cat \# 05 M0175) and stopped drilling immediately upon observing perilymph exiting around the bit. The tip of a 12-cm length of fused silica tubing (144 $\mu \mathrm{m}$ OD, $75 \mu \mathrm{m}$ ID; World Precision Instruments) was then inserted into the cochleostomy. Two approaches were taken to ensure drug infusion into the cochlea. In early experiments, dental cement was applied to seal the hole and to secure the tubing to the cochlea. In later experiments, a second hole was drilled into the base of the skull near the foramen magnum (in the clivus of the occipital bone, which is accessible via the ventral approach to the cochlea). The presence of this second hole markedly reduced the outflow of perilymph/CSF through the cochlea allowing rapid access to the afferent synapse of drug solutions infused into the cochleostomy. It also eliminated the need to seal the tube into the cochleostomy and allowed use of higher infusion rates.

An infusion/withdrawal syringe pump (Harvard Apparatus PHD 2000) was operated at an infusion flow rate of $1 \mu \mathrm{l} / \mathrm{h}$ when a single cochleostomy was made and sealed or $10 \mu \mathrm{l} / \mathrm{h}$ when an outlet had been made in the cranial cavity and the cochleostomy was not sealed. The infusion system has been previously described in detail (Chen et al. 2006). We manufactured a miniature manifold with two inputs and one output. The output was connected to the silica tubing, which was inserted into the cochleostomy. One of the inputs to the manifold was connected to an open/ shut "drain" valve and the other ultimately to the pump. A three-way valve placed between the pump and manifold allowed loading of sample in the system. To load the injection solution, the drain valve was opened, and the new solution was loaded through the three-way valve into the tubing between the pump and manifold. It was important that the resistance of the line from the manifold to the cochlea be relatively high compared to the drain line from the manifold to prevent fluid loaded into sample loop from entering the cochlea. This was easily tested on the bench beforehand by loading a dye into the system. To infuse the loaded sample into the cochlea, the drain valve was closed and the three-way valve opened to allow flow between the pump and fused silica tube via the manifold.

Physiological test. Mice were anesthetized with ketamine $(100 \mathrm{mg} / \mathrm{kg}$, i.p.) and xylazine $(10 \mathrm{mg} /$ $\mathrm{kg}$ i.p.). Acoustic stimuli $(8-45 \mathrm{kHz})$ were delivered via a custom acoustic assembly consisting of two dynamic drivers as sound sources and a miniature electret microphone to measure sound pressure in situ. Auditory brainstem responses (ABRs) were recorded via subdermal needle electrodes (vertexventrolateral to the pinna of the test ear with a ground at the base of the tail). The response from the electrodes was amplified $(\times 10,000)$, filtered $(0.1-$ $3 \mathrm{kHz}$ bandpass), and averaged (512 samples at each frequency-level combination). Sound level was incremented in $5 \mathrm{~dB}$ steps, from $\sim 10 \mathrm{~dB}$ below threshold to $90 \mathrm{~dB}$ SPL. Threshold for ABR was defined as the lowest stimulus level at which a repeatable wave could be identified in the response waveform. Distortion product otoacoustic emissions (DPOAEs) were recorded for primary tones (f1, f2) over the same $\mathrm{f} 2$ range of frequencies, with a frequency ratio of 1.2 and with the level of the f2 
primary $10 \mathrm{~dB}$ less than $\mathrm{f} 1$ level. Primaries were incremented together in $5 \mathrm{~dB}$ steps from $\sim 10 \mathrm{~dB}$ below threshold to $80 \mathrm{~dB}$ SPL. Ear canal sound pressure was amplified and digitally sampled, FFTs were computed and averaged, and the 2f1-f2 DPOAE and surrounding noise floor were extracted. Isoresponse contours were interpolated from plots of response amplitude vs sound level. Threshold was defined as the $\mathrm{fl}$ level required to produce a DPOAE of $-5 \mathrm{~dB}$ SPL. In each animal, we looked only at the response from the right ear.

\section{RESULTS}

\section{Measurement of kainate receptor mRNA}

We determined the presence and levels of expression of GluK1-5 receptor mRNA in cochlear tissue comprising the organ of Corti and spiral ganglion from adult mice. We detected mRNA for all five Grik receptors (Fig. 1). Expression levels of Grik5 mRNA were overwhelmingly higher than the others. We also measured the changes in expression of mRNA for kainate receptor subunits in the cochlea/spiral ganglion during development from as early as E15.5 though P90 (Fig. 2). Grik1 and Grik5 showed large decreases in mRNA expression shortly after birth, being expressed in much higher amounts at E17.5 and E18.5 compared to the adult level of expression. Grik1 and Grik5 mRNA amounts dropped to near adult levels by P7-P14. We did not evaluate embryonic changes in Grik2 and 3 mRNA levels.

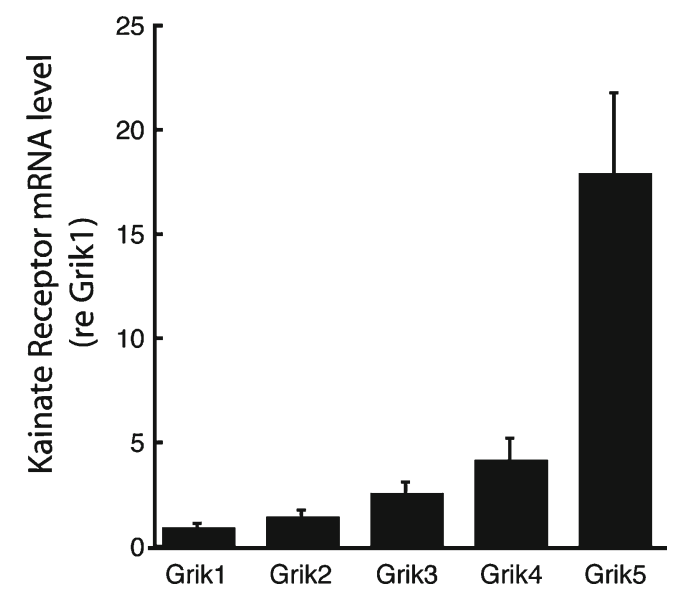

FIG. 1. mRNA levels for the kainate receptor subunits Grik1-5 in the adult (P90) CBA mouse cochlea. Quantities are normalized relative to the amounts observed for Grik1 and are expressed as mean \pm SE. Each bar plot represents measurements from nine different mice. One-way ANOVA with Bonferroni correction indicated that Grik5 levels were significantly $(p<0.0001)$ higher than the others and that Grik1 was significantly $(p<0.0001)$ lower than all of the others except Grik2.

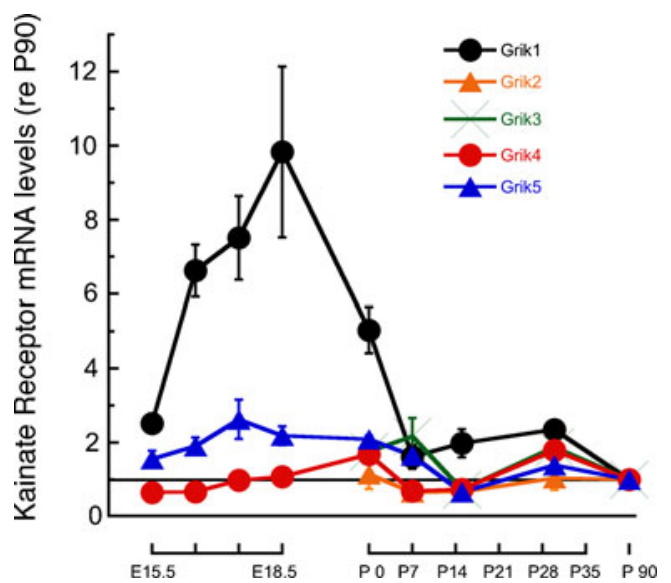

FIG. 2. Changes in kainate receptor subunit expression during development from E15.5 though P90 CBA mice. mRNA levels for each kainate receptor subunit are normalized to the level for that subunit measured at P90. Grik1 was expressed in significantly higher amounts during the embryonic stage $(p<0.001$; one-way ANOVA with Bonferroni correction) and then subsequently downregulated after birth. Measurements were made from 37 embryos and postnatal $(<5$-weekold) mice generated from nine female mice and from 30 adult (P90) mice.

\section{Distribution of kainate receptors by immunohistochemistry}

We examined the distribution of kainate receptor subunits in the cochlea by comparing immunolabel for those receptor subunits with that of GluA2, an AMPA receptor subunit present in the afferent nerve terminals (Matsubara et al. 1996; Eybalin et al. 2004). Immunolabel for both the AMPA and kainate receptor subunits was found in intense puncta at the base of the inner hair cells (Fig. 3) in what appeared to be synaptic plaques. All five kainate receptor subunits were found along with AMPA (GluA2) receptor in the synaptic plaques. These synaptic plaques were, on average, $0.37 \mu \mathrm{m}^{2}$ (standard deviation $=0.20 \mu \mathrm{m}^{2}$ ), or approximately $0.35 \mu \mathrm{m}$ in diameter. There was a wide range in sizes as indicated in the large standard deviation. The synaptic plaques generally contained both kainate and AMPA receptor immunolabeling, suggesting that virtually all terminals contained both kainate and AMPA receptors. We did not observe labeling for either AMPA (GluA2) or any kainate receptor subunits in the outer hair cell region.

When AMPA and kainate immunolabeling are superimposed (as in row 2 of Fig. 3), it is apparent that some of the terminals were more heavily labeled for the AMPA receptor while others were more heavily labeled for the kainate receptor, suggesting that in some plaques, the AMPA (red) receptor dominated while in others, the kainate receptor (green) dominated. However, when the two labels are displayed separately (rows 3 and 4 of Fig. 3), it is apparent that both AMPA and kainate receptors are both present in the synaptic plaques. 


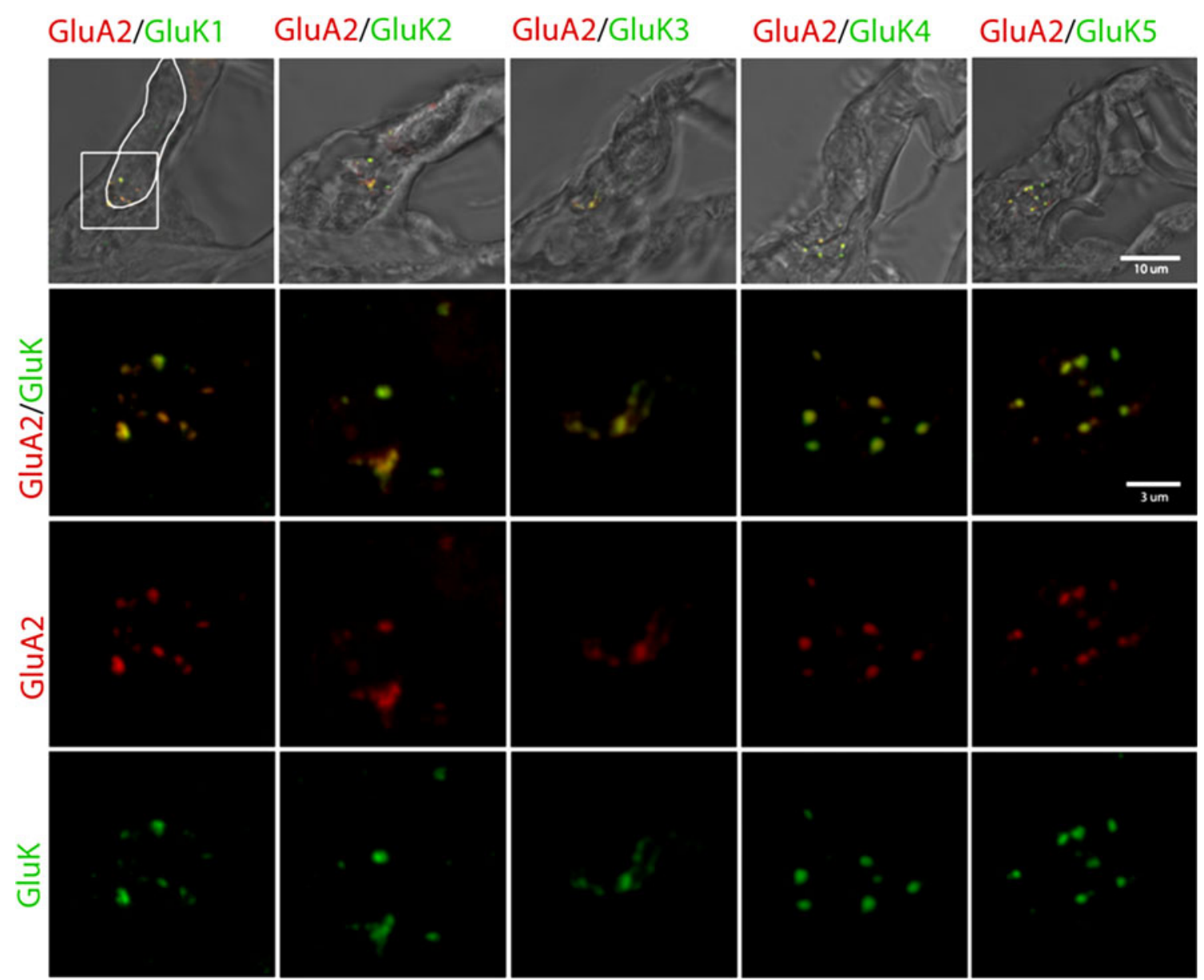

FIG. 3. AMPA and kainate receptor subunits in terminals at the base of the hair cells. Immunolabeling showed extensive overlap between the AMPA and kainate receptors. Top row a series of confocal fluorescence slices through each $10 \mu \mathrm{m}$ tissue section was averaged and superimposed on a single light microscopy confocal slice to show the location of AMPA (GluA2, red, subunit) and kainate (subunits indicated for each column, green) at the base of the inner hair cell. The approximate location of the inner hair cell is indicated in white outline on the top left panel. All sections are oriented similarly with the longitudinal axis of the inner hair cell projecting

The immunolabeling pattern presented in Figure 3 is an average of all of the confocal Z-slices (typically $0.5 \mu \mathrm{m}$ spacing) through a $10-\mu \mathrm{m}$ tissue section. To eliminate the possibility that the differential labeling of terminals was due to an artifact of the tissue depth of the terminal, we examined terminals within single confocal slices for the presence of different ratios of kainate to AMPA receptor. Even within a single confocal slice, different terminals varied with respect to which receptor (AMPA or kainate) dominated the immunolabeling appearance. This is evident in Figure 4, where many individual examples of merged (AMPA and kainate immunolabel) images for each of the kainate receptor subunits are presented. As was the case for examples shown in Figure 3, both recep- from lower left to upper right. Though only a single light microscopy slice through the section is shown for clarity, each midmodiolar tissue section contained in general 1.5 to 2 hair cells. Second row the synaptic region (indicated with the white box on the upper left image) is magnified 3-fold and only the merged fluorescence portion of the image is presented. Third and fourth rows show AMPA (GluA2, red) and kainate (green) label separately for the same sections. The scale bar is $10 \mu \mathrm{m}$ in the first row and $3 \mu \mathrm{m}$ for the bottom three rows; 8-12-week-old CBA/CaJ mice were used for immunohistochemical analyses.

tors were generally observed in the terminal when the unmerged images were examined (data not shown).

To assess whether the AMPA-receptor- or kainatereceptor-dominated synaptic plaques represented separate populations of afferent neurons, we quantified the area of the synaptic plaques and the fluorescence intensity of AMPA and kainate labeling in each to provide a ratio of AMPA (GluA2) to kainate receptor for each of the kainate receptor subunits. In an individual confocal slice, the relative intensity of either red label or of the green label could be compared among terminals, but because the relative intensity of red to green depended on a broad range of factors (from immunolabeling chemistry, to sensitivity of the confocal scanner), ratios of red to green 


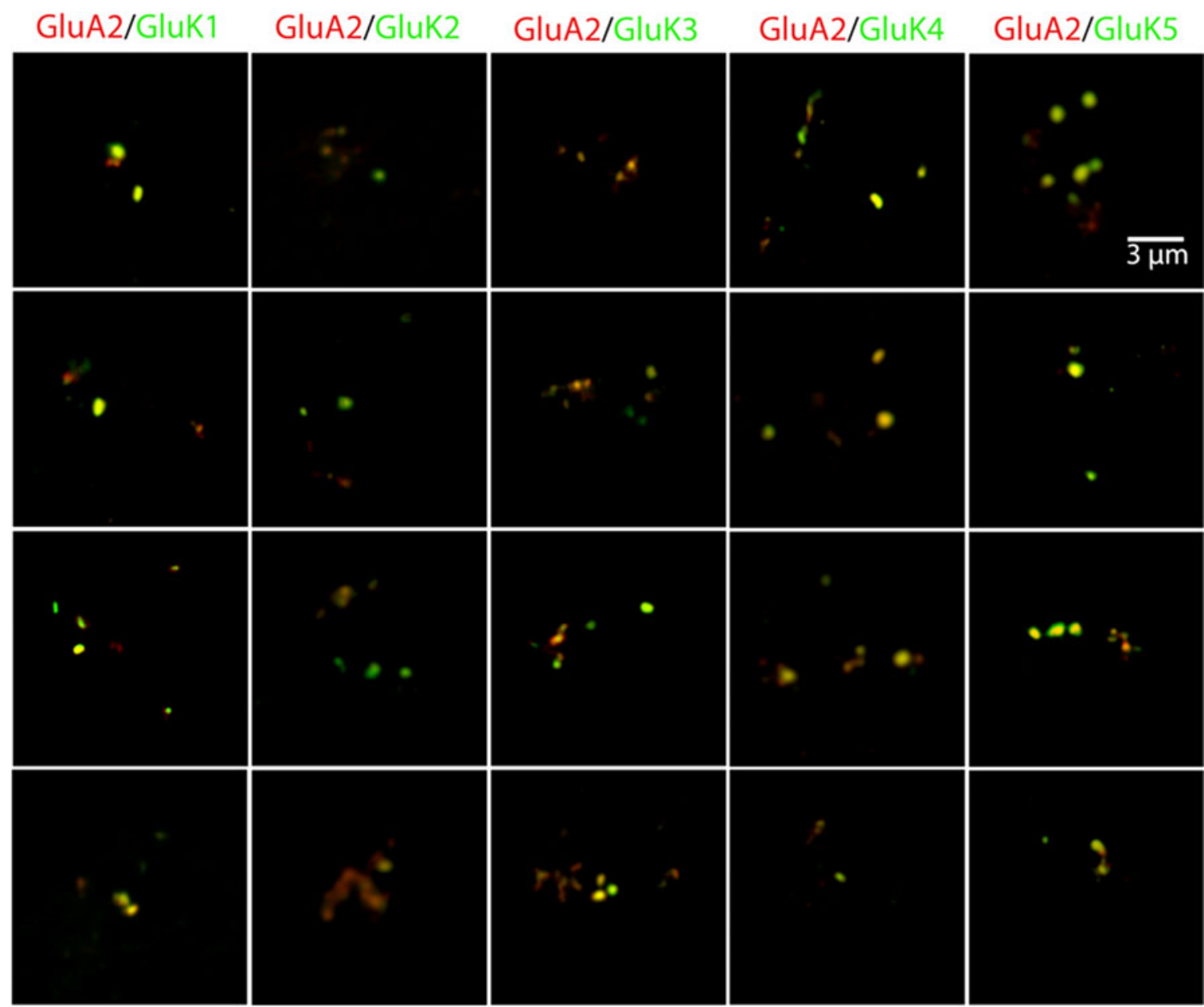

FIG. 4. Immunolabel for AMPA and kainate receptors in single confocal slices. Even in single confocal slices, the pattern of AMPA (GluA2 subunit, red) or kainate (each subunit displayed in a different row) receptor domination in different synaptic plaques is evident. Orientation of the tissue slices is the same as that shown in Figure 3, with longitudinal axis of the hair cell from lower left (base) to upper right (apex). Images are organized by columns for each kainate

in each section were normalized to the mean ratio for all terminals in that section. From each tissue section, we chose a single confocal slice for analysis. The normalized ratios of AMPA/kainate were then compiled for all observations and plotted in Figure 5 for each of the kainate receptor subunits. If there were two or more populations of terminals with different ratios of AMPA/kainate, we would have expected to observe a bimodal or multimodal distribution. However, the distribution appeared to be unimodal for all of the subunits, suggesting a single population of neurons with varying ratios of AMPA/kainate receptor. We observed no correlation between the size of the synaptic plaque and the ratio of AMPA/kainate immunoreactivity.

While each synaptic plaque contained both AMPA (GluA2) and kainate receptor subunits, the two did not always superimpose within the plaque. Some regions of the plaque could be enriched for AMPA or receptor subunit, with different examples shown in each row. Each image is from a different cochlear preparation and shows a merged image of label for AMPA and kainate subunits. While some synaptic plaques were dominated by AMPA and others by kainate, when the merged image is separated (not shown), the plaques show both kainate and AMPA immunolabeling in all the terminals. The scale bar of $3 \mu \mathrm{m}$ shown in the upper left panel applies to all panels.

for kainate receptor, as if the different receptor subtypes could sometimes be clustered. Some examples, where the separate clustering of AMPA and kainate receptor subunits was especially prominent, are shown in Figure 6 at very high magnification. However, in most terminals, the general pattern of labeling overlapped.

\section{Pharmacology}

To evaluate the functional role of kainate receptors in afferent transmission, we infused the scala tympani of the mouse cochlea with an antagonist for the kainate receptor, UBP296, while monitoring the neural responses (compound action potentials (CAPs)) to tone pips. If kainate receptors were participating in afferent transmission, then pharmacologic block of the receptors should attenuate afferent transmission and reduce the neural response. Infusion of an 

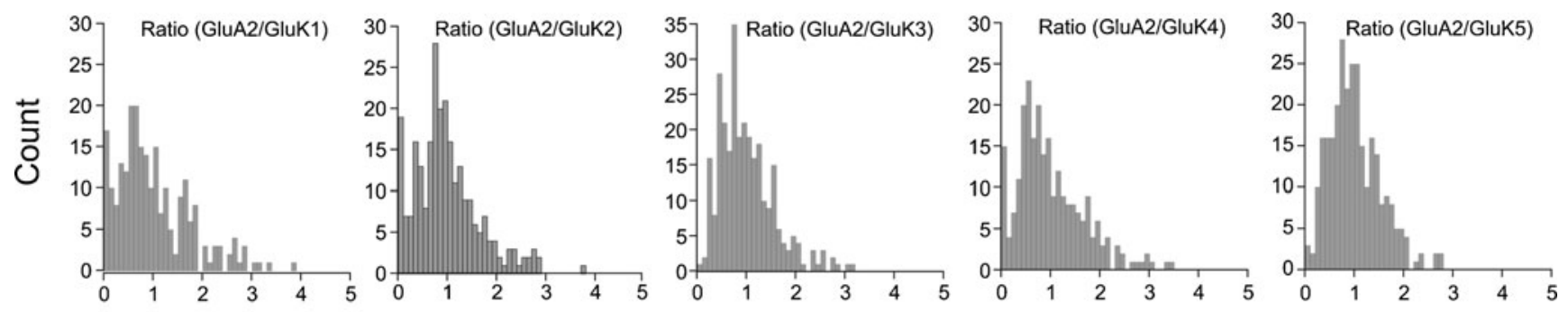

\section{Ratio (AMPA/Kainate Receptor)}

FIG. 5. Histograms of the ratios of AMPA (GluA2) to kainate receptor immunoreactivity are shown for each receptor subunit. For each tissue section, the merged image of a single confocal slice was chosen for analysis. Each labeled terminal was demarcated, and the average fluorescence intensity of AMPA and kainate receptor subunit label was

artificial perilymph (carrier) solution did not affect thresholds or CAP amplitudes. Infusion of UBP296 elevated thresholds for the CAP (Fig. 7a). As a control for nonspecific effects on cochlear function, we made concurrent measurements of UBP296 on DPOAEs, which are primarily generated by the outer hair cells and thus not likely to be affected by block of afferent neurotransmission. DPOAEs were relatively unaffected, suggesting the effects were indeed at the afferent synapse. Panel B of Figure 7 shows the UBP296-

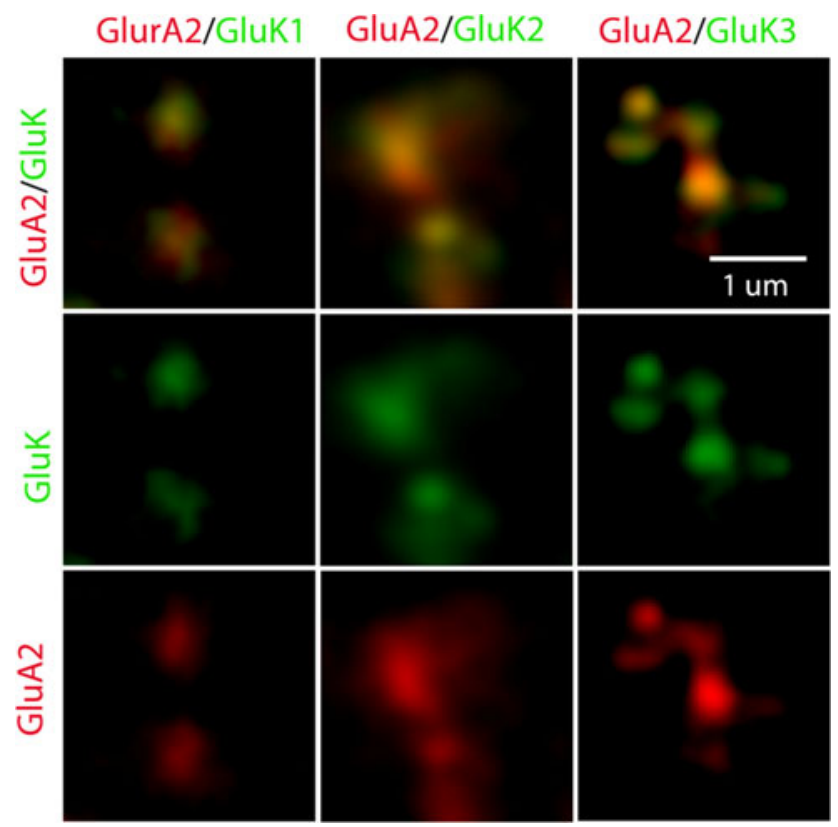

FIG. 6. Examples of synaptic plaques showing non-overlapping distribution of GluA2 and kainate receptor subunits. While all synaptic plaques contained both GluA2 and GluK receptor subunits, the pattern of labeling within a plaque did not always precisely overlap. This is especially prominent in the merged images (top row). Each set of images shows clusters of synaptic plaques at the base of the inner hair cell. Though images were taken with from a single confocal slice, convolution intrinsic to the image acquisition process coupled to the relatively high density of plaques at the base of the hair cell makes some of the plaques appear lobulated in the images, but in reality, these are separate synaptic plaques. The scale bar of $1 \mu \mathrm{m}$ in the upper left panel applies to all panels. quantified to create the ratio of GluA2/GluK label. Each histogram was created from measurements of eight to 14 tissue sections. For all GluK subunits, the ratios of GluA2/GluK presented a unimodal distribution centered around unity, suggesting a single (vs bimodal) population of terminals based on dominance of AMPA vs kainate receptor.

induced reduction in amplitude of the CAP associated with threshold shifts shown in panel A. As indicated in panel C of Figure 7, UBP296 produced a concentration-dependent reduction in CAP amplitude with an EC50 similar to that observed with infusion of CNQX, a broad spectrum AMPA/kainate receptor blocker. While not shown here, our results were consistent with our previously published characterization of the effects of CNQX on afferent responses (Chen et al. 2006), in which effects of drugs are larger on responses generated in higher-frequency regions of the cochlea, which are closer to the site of infusion.

\section{DISCUSSION}

All five kainate receptor subunits (GluK1-5) appear to be present in the cochlea, based on both quantitative RT-PCR and on immunohistochemistry. There are some general observations that apply to all of the glutamate receptor immunolabeling we observed. First, intense immunolabel for AMPA (GluA2) and kainate receptor subunits was found in puncta at the base of the inner hair cells. The puncta were about the right size (approximately 0.1 to $0.5 \mu \mathrm{m}$ in diameter) to be synaptic plaques found postsynaptically in afferent terminals (Merchan-Perez and Liberman 1996). Second, all five kainate receptor subunits were found along with GluA2 in the synaptic plaques. Third, the terminals varied in whether immunolabel for the AMPA receptor or the kainate receptor dominated. This was noted even within single confocal slices (optical sections). The distributions of AMPA/kainate ratios were unimodal for all five receptor subunits, suggesting a variance of ratios within a single population of auditory terminals, as opposed to multiple populations of terminals with different ratios of AMPA to kainate receptor. Fourth, while each synaptic plaque contained both AMPA (GluA2) and kainate receptor subunits, they did not 
A

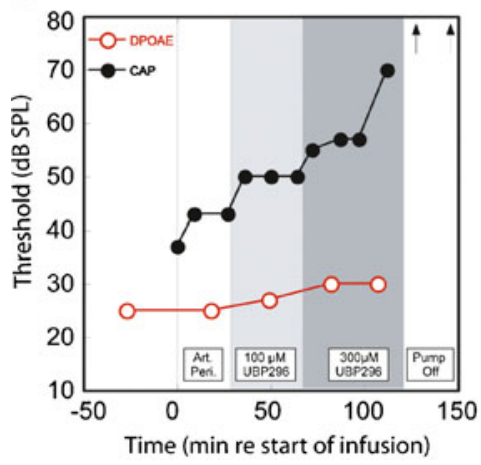

B

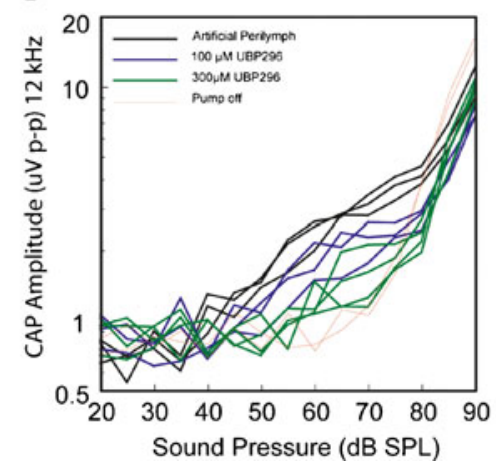

C

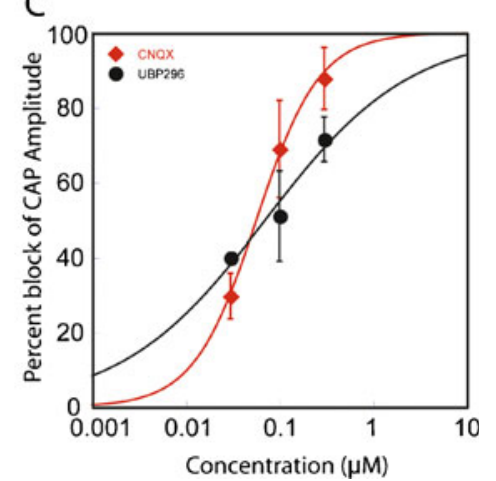

FIG. 7. Infusion of UBP296, a specific kainate (GluK1) receptor antagonist, into the mouse cochlea reduced the amplitude of the CAP in a concentration-dependent manner. An example of the time course of the changes in CAP and DPOAE thresholds at $12 \mathrm{kHz}$ with infusion of UBP296 is presented in A. After a 40min period of infusion with an artificial perilymph solution (Art. Peri.), the cochlea was infused with $100 \mu \mathrm{M}$ UBP296 for $40 \mathrm{~min}$, followed by infusion with $300 \mu \mathrm{M}$ UBP286 for $1 \mathrm{~h}$. UBP286 produced large changes in CAP threshold with relatively small changes in DPOAE threshold. Arrows indicate time points where neural responses were no longer observed. The elevations in threshold by UBP296 reflect its ability to reduce the amplitude of the CAP, shown in B. Note that by the end of the infusion with $300 \mu \mathrm{M}$ UBP296 (red lines), no neural response is observed and all of the peak to peak amplitude is associated with the summating potential (a reflection of the inner hair cell response). In C, the reduction in CAP amplitude with UBP296 for all animals tested is compared to that with CNQX, a broad spectrum AMPA/kainate receptor antagonist delivered with the same approach. A sigmoidal dose response curve was fit to both the CNQX and UBP296 data. where $n$ is the steepness of the curve. $\mathrm{EC}_{50}$ 's for CNQX and UBP296 were 57 and $71 \mu \mathrm{M}$, respectively. always exactly superimpose-regions of the plaque could be enriched for AMPA or for kainate. In summary, all of receptor subunits appeared to colocalize with AMPA (GluA2), suggesting the presence of kainate receptors at the afferent synapse.

There are also several limitations to interpreting the roles of kainate receptor subunits in cochlear afferent transmission. First, our analysis of mRNA quantified all five subunits in extracts of cochlear tissue, which included spiral ganglion cells. However, the analysis of mRNA does not indicate where the proteins subsequently generated are destined to be located. Possibilities include presynaptic receptors on the auditory nerve terminals in the cochlear nucleus, postsynaptic receptors on auditory neurons at the hair cell synapse, and presynaptic receptors on hair cells. Immunochemical analysis confirmed the presence of these receptors at the hair cell auditory nerve synapse. Co-immunolocalization with AMPA receptors suggests that they are located postsynaptically, but we cannot entirely rule out the possibility that some kainate receptor labeling is presynaptic on the hair cell. We did not examine spiral ganglion terminals on the cochlear nucleus. Second, we have no independent corroboration of the subunit specificity of the antibodies we have used. The antibodies proved unsuitable for western blot analysis, and the nearly identical sizes of the different subunits decreases the practicality of that approach. Detection of the kainate receptor subunits required amplification of the antibody signal through the use of a biotin-avidin-streptavidin amplification step. We were unsuccessful in developing an alternate amplification step that would allow us to simultaneously examine two kainate receptor subunits. Ultimately, the use of knockout animals will allow a determination of specificity of subunit antibodies.

The pharmacological evidence, attenuation of sound-evoked neural responses with cochlear infusion of UBP296, is consistent with the idea that kainate receptors are contributing to the synaptic response. The dose-response curves suggest that UBP296 was similar in potency to CNQX, with both drugs producing a 50\% block of CAP amplitude at around $100 \mu \mathrm{M}$. CNQX is a broad spectrum AMPA/kainate receptor antagonist, with similar affinities for AMPA and kainate receptors $\left(K_{\mathrm{d}} \mathrm{s}\right.$ on the order of 0.3307 and $1.5 \mu \mathrm{M}$ respectively (Honore et al., 1988)). UBP296 is considered a selective kainate receptor antagonist with a 100-fold stronger affinity for the kainate receptor $\left(K_{\mathrm{d}}=1.1 \mu \mathrm{M}\right)$ than the AMPA receptor $\left(K_{\mathrm{d}}=98 \mu \mathrm{M}\right)$ (More et al. 2004). In general, drugs infused in the cochlea require much higher concentrations to act than their $K_{\mathrm{d}}$ (usually determined in isolated cells) would suggest. Both CNQX and UBP296 are active in the cochlea at over 100-fold higher concentrations than their lowest $K_{\mathrm{d}}$ 's. Our observation of equivalent potencies for CNQX and UBP296 are consistent with, though not proof of, a role of kainate receptors in cochlear afferent transmission. Defining the relative contributions of the two receptor subtypes will require a more extensive pharmacological analysis of these types of drugs.

While UBP296 is known to bind to the GluK1 subunit, its binding to that subunit will block receptor activity in the whole heteromeric receptor (More et al. 2004). However, some caution is warranted as the 
specificity of these agents can vary depending on kainate receptor subunit combination, and many subunit combinations have not been examined (More et al. 2004; Pinheiro and Mulle 2006). Similar caution should apply in interpreting observations that afferent transmission is attenuated with GYKI53784 and NBQX (Ruel et al. 2000; Grant et al. 2010) (agents that have a greater specificity for AMPA than kainate receptors).

Kainate receptors form tetramers of homomeric or heteromeric units, though GluK4 and GluK5 subunits are not themselves active, and must be combined with one or more GluK1-2 subunits (Pinheiro and Mulle 2006; Jane et al. 2009). Our observation of all five subunits in the cochlea both with quantitative RT-PCR and with immunohistochemistry raises the question of which four subunits are combining to form the tetrameric receptor. We observed all five receptor subtypes on afferent terminals and did not observe any differences in their patterns of expressions. So we cannot make a reasonable prediction of the composition of the subunits in the kainate receptors in the cochlea. A previous RT-PCR and in situ hybridization analysis of kainate receptor subunits in rat cochlear ganglion by Niedzielski and Wenthold (1995) observed all but the GluK3 subunit. It is possible that some of the antibodies we used may have reacted with GluK subunit other than those to which they were created, so that we may have erroneously attributed one or more subunits to the hair cell synapse, when in fact its presence in our mRNA analysis may have been associated with role in the axonal terminal in the cochlear nucleus.

We noted relatively very large decreases in the expression of the Grik1 and modest decreases in Grik5 subunits during late embryonic development and early postnatal growth, suggesting a changing subunit composition in the kainate receptors as the animal develops hearing. Our observations suggest that mRNA production for Grik 1 and 5 has dropped to adult expression levels by $\mathrm{P}$ 7, though change in the receptor composition may not be evident for some time after that. Grant et al. (2010) showed probabilistic changes in the waveform shapes of excitatory postsynaptic potentials recorded in immature vs mature rats. Immature rats showed more multiphasic EPSPs with slower rise times and smaller amplitudes while mature rats had more monophasic EPSPs. It is possible that the increased proportion of GluK1 and GluK5 kainate receptor subunits we observed in the immature cochleas could contribute to some of these differences.

One might expect kainate and AMPA receptors to have different response characteristics to neurotransmitter released from the hair cells. While affinity of glutamate for the two receptor types is similar, other receptor properties that might differ could include the amount of current associated with activation and the desensitization characteristics: Generally, kainate receptors are slower, with longer open times and with 10-fold slower desensitization characteristics (Dingledine et al. 1999).

We also noted that even for a single hair cell, the afferent terminals innervating that hair cell ranged widely in whether they were dominated by kainate or AMPA receptors. Biophysical recordings of synaptic activity (Grant et al. 2010) show heterogeneity in EPSC amplitudes varying among different afferent fibers. It is plausible that some of this difference is associated with diversity in relative ratios of AMPA to kainate receptor that we have observed. A comparison of synaptic ribbon areas to AMPA (GluA2/3) receptor areas in the mouse synapse (Liberman et al. 2011) showed that larger synaptic ribbons, generally associated with low spontaneous discharge rates in afferent fibers (Merchan-Perez and Liberman 1996), were associated with smaller GluA2 plaques while large synaptic plaques were associated with the smaller ribbons. They suggest that fibers with larger plaques of AMPA receptors may have higher spontaneous discharge rates and suggest that a complementary receptor may be present postsynaptically in the low spontaneous rate units. If so, kainate does not appear to be that receptor since AMPA (GluA2) and kainate receptor distribution largely overlap (with the exception of a few cases such as seen in Fig. 6).

It is possible that the differences in relative ratios of AMPA to kainate receptor that we observed are a dynamic process. We have previously shown that the AMPA receptor (GluA2 subunit) was actively regulated in response to changes in acoustic stimulation (Chen et al. 2007). mRNA levels of the kainate receptor subunits varied widely (Fig. 1) with Grik5 being much higher than the others. Because mRNA levels reflect the process of generation of new protein, the finding suggests that the GluK5 subunit may be turned over more than the others and thus might control the activity of the endogenous heteromeric kainate receptor.

Kainate receptors are colocalized in afferent terminals of the mouse auditory nerve with AMPA receptors. If the affinities of kainate and AMPA receptors to the neurotransmitter released by the hair cell are similar, as they appear to be in other systems (Dingledine et al. 1999), then it is reasonable to assume that the kainate and AMPA receptors are both activated with release of synaptic vesicles from the hair cell and that both contribute to the response of auditory nerve fibers. In the final analysis, the presence of both kainate and AMPA receptor subtypes colocalized in the afferent terminals must be considered in understanding postsynaptic processing of auditory information. 


\section{ACKNOWLEDGMENTS}

The work was supported by the NIDCD (grant \# DC00767). We thank M. C. Brown and M. C. Liberman for comments and critiques of the manuscript.

\section{REFERENCES}

Bleakman D, Ballyk BA, Schoepp DD, Palmer AJ, Bath CP, Sharpe EF, Woolley ML, Bufton HR, Kamboj RK, Tarnawa I, Lodge D (1996) Activity of 2,3-benzodiazepines at native rat and recombinant human glutamate receptors in vitro: stereospecificity and selectivity profiles. Neuropharmacology 35:1689-1702

Chen Z, Mikulec AA, McKenna MJ, Sewell WF, Kujawa SG (2006) A method for intracochlear drug delivery in the mouse. J Neurosci Meth 150:67-73

Chen Z, KuJawa SG, Sewell WF (2007) Auditory sensitivity regulation via rapid changes in expression of surface AMPA receptors. Nat Neurosci 10:1238-1240

Collingridge GL, Olsen RW, Peters J, Spedding M (2009) A nomenclature for ligand-gated ion channels. Neuropharmacology $56: 2-5$

Dingledine R, Borges K, Bowie D, Traynelis SF (1999) The glutamate receptor ion channels. Pharmacol Rev 51:7-61

Eybalin M, Caicedo A, Renard N, Ruel J, Puel JL (2004) Transient $\mathrm{Ca} 2$ + -permeable AMPA receptors in postnatal rat primary auditory neurons. Eur J Neurosci 20:2981-2989

Glowatzki E, Grant L, Fuchs P (2008) Hair cell afferent synapses. Curr Opin Neurobiol 18:389-395

Grant L, YI E, GLowatzki E (2010) Two modes of release shape the postsynaptic response at the inner hair cell ribbon synapse. J Neurosci 30:4210-4220

Honore T, Davies SN, Drejer J, Fletcher EJ, Jacobsen P, Lodge D, NiELSEN FE (1988) Quinoxalinediones: potent competitive non-NMDA glutamate receptor antagonists. Science 241:701-703

Jane DE, Lodge D, Collingridge GL (2009) Kainate receptors: pharmacology, function and therapeutic potential. Neuropharmacology 56:90-113
Knipper M, Kopschall I, Rohbock K, Kopke AK, Bonk I, Zimmermann U, ZENNER H (1997) Transient expression of NMDA receptors during rearrangement of AMPA-receptor-expressing fibers in the developing inner ear. Cell Tissue Res 287:23-41

Liberman LD, WANG H, Liberman MC (2011) Opposing gradients of ribbon size and AMPA receptor expression underlie sensitivity differences among cochlear-nerve/hair-cell synapses. J Neurosci 31:801-808

Matsubara A, Lake JH, Davanger S, Usami S, Ottersen OP (1996) Organization of AMPA receptor subunits at a glutamate synapse: a quantitative immunogold analysis of hair cell synapses in the rat organ of Corti. J Neurosci 16:4457-4467

Mayer ML, Ghosal A, Dolman NP, Jane DE (2006) Crystal structures of the kainate receptor GluR5 ligand binding core dimer with novel GluR5-selective antagonists. J Neurosci 26:2852-2861

Merchan-Perez A, Liberman MC (1996) Ultrastructural differences among afferent synapses on cochlear hair cells: correlations with spontaneous discharge rate. J Comp Neurol 371:208-221

More JC, Nistico R, Dolman NP, Clarke VR, Alt AJ, Ogden AM, Buelens FP, Troop HM, Kelland Ee, Pilato F, Bleakman D, Bortolotto ZA, Collingridge GL, Jane DE (2004) Characterisation of UBP296: a novel, potent and selective kainate receptor antagonist. Neuropharmacology 47:46-64

Moser T, NeEf A, Khimich D (2006) Mechanisms underlying the temporal precision of sound coding at the inner hair cell ribbon synapse. J Physiol 576:55-62

NiEdZIELSKI AS, WeNTHOLd RJ (1995) Expression of AMPA, kainate, and NMDA receptor subunits in cochlear and vestibular ganglia. J Neurosci 15:2338-2353

Pinheiro P, Mulle C (2006) Kainate receptors. Cell Tissue Res 326:457-482

Ruel J, Bobbin RP, Vidal D, Pujol R, Puel JL (2000) The selective AMPA receptor antagonist GYKI 53784 blocks action potential generation and excitotoxicity in the guinea pig cochlea. Neuropharmacology 39:1959-1973

Ruel J, Wang J, Rebillard G, Eybalin M, Lloyd R, Pujol R, Puel JL (2007) Physiology, pharmacology and plasticity at the inner hair cell synaptic complex. Hear Res 227:19-27

Seal RP, Akil O, Yi E, Weber CM, Grant L, Yoo J, Clause A, Kandler K, Noebels JL, Glowatzki E, Lustig LR, Edwards RH (2008) Sensorineural deafness and seizures in mice lacking vesicular glutamate transporter 3. Neuron 57:263-275 